\title{
Research Progress on Synergic Innovation Theory - A Literature Review
}

\section{Kai Hu* and Meng-Er Tu}

College of Economics and Management, Jiangxi Agricultural University, Nanchang 330045, China

\begin{abstract}
Synergic innovation is a new paradigm, and a new progress of innovation system theory. We reviewed the evolution of innovation theory, analyzed the background of synergic innovation theory. The study on synergic innovation has been expanded from inside to outside, covered three fields, which was synergic innovation within enterprise, vertical synergic innovation inter-enterprise, horizontal synergic innovation within multi-agents. Horizontal synergic innovation is the main form of synergic innovation. Factors of synergic innovation expanded from the "University-industry-government". Different methods have been developed to measure the synergic innovation effect and synergic degree. Furthermore influential factors and decision mechanism of synergic innovation behavior has been studied.
\end{abstract}

Keywords: Horizontal synergic innovation; Synergic innovation effect; Degree of synergic; Influential factors; Decision mechanism

\section{Introduction}

Nowadays, knowledge became increasingly divergent, a single company was difficult to conduct R\&D rely on itself [1]. Innovation was no longer separate activities, but dynamic and complicated integrated activities which related to multi-level, multi-agent, multi-stage and a variety of innovative elements [2]. Synergic innovation has become the key factor of enterprise rapidly accessed to technology advantage [3], as a new innovation paradigm, synergic innovation has gradually become a hot topic around the world.

\section{Evolution of Innovation Theory and Background of Synergic Innovation Theory}

Schumpeter pointed out that innovation was the source of modern economic growth, and a kind of creative destruction. Since then, more and more scholars studied on theory of innovation. With the progress of science and technology, innovation became increasingly complex, presented a multi subject participation and complex feature.

Jonathan [4] analyzed the history of human science and technology innovation; found that a new technology in $20^{\text {th }}$ century was harder than $19^{\text {th }}$ century, because of limitation of economic and physical. Innovation increasingly relied on collective behavior and network relationship, multi-agent collaborative innovation was the most effective path [5].

Freeman [6] raised the concept of national innovation system (NIS), considered NIS as a network which composed by various institutions in public sector and private sector. Interaction effect of these institutions would promote the development, introduction, improvement and diffusion of new technology.

Lundvall [7] regarded innovation as a whole system that various factors related each other. OECD [8] stated that innovation and technology progress was the consequence of a complex relationship between the main bodies of knowledge production, distribution and application, and innovation performance of a country depended on the way how these main bodies connected to be a knowledge innovation aggregation. Later, system approach of innovation expanded to the regional level. Cooke [9] proposed the concept of regional innovation system (RIS), and defined it as an interactive learning system that formed by enterprises and other organizations under the institutional environment characterized as embeddedness. Innovation was the result of complex interactions between regional, national and even hypernational organizations [10]. A single company was difficult to conduct
R\&D rely on itself, organizations should use both internal and external ideas, share risk and benefit with partners. Chesbrough proposed the openness innovation model. The boundary of organization's innovation activities was fuzzy, the enterprise's profitability depended on the ability of acquire innovation resources from external and convert it into commercial value.

Haken proposed the idea of synergetics, which been gradually applied to synergic innovation theory [11]. Synergic innovation was the new progress of National Innovation System theory [12].

\section{Connotation and features of synergic innovation}

Connotation of synergic innovation: Persaud [13] pointed out that synergic innovation was the collaborative progress based on research and development (R\&D) cooperation between multi participants to elevate enterprise's innovation abilities. Synergic innovation ability included four dimensions which were R\&D strategic synergy, operational management synergy, knowledge management synergy and innovation skill synergy. Serrano and Fischer described synergic innovation as a process to achieve new product R\&D. During the process, the partners shared information, made plan and solved key technical problems together.

Synergic innovation was aimed at knowledge increment. In order to achieve major scientific and technological innovation, enterprise, government, university, research institution, intermediary organization and user cooperated and integrated deeply, came into being superimposed nonlinear system effects. Synergic innovation was more emphasis knowledge exchange and technology transfer in innovation behavior actors [14].

Research on synergic innovation has been expanded from inside to outside, namely from collaborate within enterprise to vertical collaborate inter-enterprise and furthermore to non-vertical (horizontal) collaborate.

*Corresponding author: Kai Hu, College of Economics and Management, Jiangxi Agricultural University, Nanchang 330045, China, Tel: +3032609153; E-mail: carl-hu@163.com

Received November 12, 2015; Accepted December 15, 2015; Published December 21, 2015

Citation: Hu K, Tu ME (2015) Research Progress on Synergic Innovation Theory A Literature Review. Int J Econ Manag Sci 5: 307. doi:10.4172/21626359.1000307

Copyright: @ $2015 \mathrm{Hu} \mathrm{K}$, et al. This is an open-access article distributed under the terms of the Creative Commons Attribution License, which permits unrestricted use, distribution, and reproduction in any medium, provided the original author and source are credited. 


\section{Types of synergic innovation}

Synergic innovation within enterprise: Synergic innovation within enterprise means collaborate between internal departments and staffs in an enterprise. Srivastava and Gnyawali indicated that quality and diversification of technology resource profile were helpful for breakthrough innovation. Enterprise should integrate innovation elements such as technology and internal resources. Hagedoorn and Schakenraad [15] thought that relationship had interaction and complementary effect in technology innovation thereby emerged more and more collaborative innovation in organization. Product innovation and supply chain process innovation efforts have traditionally been managed as separate activities, now collaborative innovation seek to integrate them, new management approaches and information technology solutions can overcome barriers that hampered collaborative innovation [16].

Synergic innovation inter-enterprise: Synergic innovation interenterprise mainly refers to a kind of vertical synergic innovation, which means innovations across firm boundaries through the sharing of ideas, knowledge, expertise, and opportunities, cooperation among supply chain members such as customer, suppliers, buyers, competitors and so on [17]. Many scholars especially emphasized the importance of "Users" to firm's innovation. Von [18] studied on user driven innovation since 1970s, put forward users should be predominance in the stage of idea formation, Charles and David believed that enterprise could cooperate with customers in different innovation stages through a variety of ways, the ability and skills of enterprise's synergic innovation was important factor for organizational success. Carliss and Eric [19] believed that both innovation by individual users and open collaborative innovation might displace producer innovation in many parts of the economy, which represented a paradigm shift with respect to innovation research, policy making, and practice. Some scholars studied the collaboration between enterprise and suppliers. In order to reduce $R \& D$ cost and time, increase product's quality and value, manufacturers incorporate upstream suppliers to product innovation or process innovation [20]. Clark and Fujimoto [21] found that this kind collaboration was conducive to cut down $\mathrm{R} \& \mathrm{D}$ time and improve product's quality. Johnsen and Ford [22] pointed out that supply chain management, partnership and network has been regarded as the best management practices by many organizations, which has a profound influence to enterprise innovation.

\section{Horizontal multi agent synergic innovation}

Horizontal multi agent synergic innovation refers to enterprise cooperation with non-supply chain numbers such as universities, research institutions, government, intermediary organizations. Industry-university-research cooperation was one of the typical forms, most studies focused on it.

Triple helix innovation theory: Etzkowitz and Leydesdorff [23] proposed triple helix innovation theory which was Industry-UniversityResearch cooperation innovation, and raised high concerns from academia, industry, and politics fields. There were three collaborative models between governments, industries and universities, respectively were national socialism, laissez-faire and overlap model. The overlap model was considered more conducive to cooperation innovation. The overlap field of university, industry and government was the core of innovation system; three parties' connection was an important factor to promote knowledge production and dissemination. Its meaning was to integrate university, enterprise and government which had different value system and function, promoted knowledge convert into productivity, drove innovation spiral siding. Entrepreneurial university was the propeller of triple helix innovation, not only the source of innovation, but also the organizer of innovation activities.

Some scholars raised criticism to triple helix innovation. Someone though that the components of triple helix mode were not complete, should not be confined to university, enterprise and government. A debate was growled at the Fourth World Triple Helix Conference in 2002, which was whether or not triple helix should be extended to fourth helix? Chunyan [24] proposed the double triple helix innovation model which was Industry-University-Research and UniversityPublic-Research, some scholars attempted to expand the quadruple even more multiple helix, added some other elements such as labor, venture capital and informal sectors. On the basis of triple helix model, Etzkowitz [25], Carayannis and Campbell [26] added two elements of public and environment, and constructed the quintuple helix innovation model based on triple helix model. Shapiro [27] argued that research institutions should replace university as the element of triple helix model. Santonen [28] considered the defect of triple helix model was that not introduced "User" as an element.

Intermediary institutions: Besides the elements of government, industry, university, capital and user, some scholars studied the function of intermediary institutions in synergic innovation. Hoppe and Ozdenoren [29] believed that intermediary institution was crucial in the marketization process of technical invention, which contribute to reduce or eliminate the uncertainty between technology inventor and adopters. University Technology Transfer Office (TTO) was very important in the Industry-University-Research cooperation, and was helpful to foster effective Industry Science Links (ISLs). Some companies even regarded skill and expertise of TTO's staff as the key factor to university-industry cooperation efficiency [30]. Debackere and Veugelers [31] analyzed the evolution mechanism of effective TTO, designed the incentive structure of university scientific research team, and studied the effective decision of TTO. Macho-Stadler etc built a theoretical model to explain the specific role of TTO to university invention licensing. Companies were inadequate understanding information quality of university's invention. Certification of TTO's reputation can reduce the information asymmetry problem about invention's quality, which will cause less but more valuable innovation be sold at a higher price, thereby make TTO get higher technology transfer income. Hellmann [32] stated that scientists could engage in scientific research and achieve specialized division through TTO.

Along with the increasing improvement of cooperative innovation level, more studies focused on joint nodes between all kinds of innovation actors. Intermediary institutions performed various tasks in innovation, which be called as third party bridges agent information and so on [33-35].

Synergic innovation was not limited in the mode of IndustryUniversity-Research, but surpassed the boundaries of traditional Industry-University-Research; it emphasized close cooperation between all the innovation actors and the synergistic effect of variant innovative elements.

\section{Synergic Innovation Effect and Measure of Synergy Degree}

Synergic innovation effect means that the whole system larger than sum of individual participants, especially the effect of complementarities and externalities, through integration resources of all partners in 
innovation process [36]. Synergic innovation effect not only depended on innovation resources, but also depended on innovation mode. Xie measured the synergic innovation effect through five indexes, regarded synergy mechanism and environment as moderator variables, analyzed the influence of synergic innovation mode to synergic innovation effect.

Scholars measured synergy degree by different methods. Leydesdorff [37] developed triple helix algorithm, a quantitative method to measure the relationship of the triple helix. The algorithm was based on Shannon comentropy, the entropy value ( $\mathrm{T}$ value) reflected synergy degree of collaboration between university, industry and government. Rejeb et al. proposed multi-criteria models to measure the innovation ability and synergy effects. Ketchen et al. [38] examined the extent to which synergy between process, content and context explained organizational performance.

\section{Influence factor and drive mechanism to synergic innovation behavior}

Scholars conducted series researches on the influence factor to synergic innovation performance, collaborative willingness, collaborative efficiency and knowledge diffusion. Simonin [39] found that the main influence factors to synergic innovation performance included alliance's cultural differences, previous experience, enterprise's absorptive capacity, knowledge type, learning barriers and alliance's relationship. Laursen and Salter [40] discovered the "inverted U" relationship between the scale of collaborative network and innovation performance, Knudsen and Nortensen found that reinforce interaction strength would slow down R\&D speed and increase R\&D cost.

Cohen and Levinthal [41] raised the concept of absorptive ability; $\mathrm{R} \& \mathrm{D}$ input could improve enterprise's technology absorptive ability. Laursen and Salter stated that enterprises with high R\&D ability were more likely to cooperate with universities.

Gerben et al. [42] reviewed recent studies on determinants of success and failure of innovation. Agreement existed on some positive impact of factors such as firm culture, experience with innovation, multidisciplinary R\&D teams. Some factors such as R\&D intensity, fierceness of competition, top management support remained ambiguity. Influence factors also included the followings: enterprise's R\&D input, research quality of academic, physical distance [43] information disclosure risk, benefit divergence, property of knowledge, management cost [44] synergic mode between university and enterprise $[45,46]$, policy support, protect of knowledge achievement, interest allocation mechanism, financing channels.

Moreover, scholars carried out in-depth research on synergy mechanism and driving mechanism of synergic innovation. Synergy mechanism was the inner mechanism and control method that caused synergic innovation effect. Synergy mechanism composed by implementation mechanism, motivation mechanism and restraint mechanism [47], which can promote the formation of self-organization. Chen considered science and technology, market, and culture was the three factors to drive synergic innovation. Cultural differences would block knowledge exchange within university-industry collaborative innovation, so cultural conflict should be effective controlled. Arza and Lopez [48] found that company's network ability rather than knowledge base was the driving force to connection of company and public research institutions. Sherwood and Covin [49] argued that benefit allocation mechanism was the key factor to IndustryUniversity-Research collaborative innovation.

\section{Research Review}

Current researches laid a solid foundation for synergic innovation theory. As a new innovation paradigm, there were some fields still remained be further studied [50-53].

First, research on synergic innovation behavior, compared with traditional cooperative innovation, synergic innovation had difference and similarities. The similarities were that both of them in essence were a kind of cooperative behavior, emphasized the cooperation and share between variety innovation actors [54-56]. But there were differences in the matter of cooperation subject, cooperation mode, benefit allocation, terms of cooperation. Researches focused on enterprise cooperation innovation behavior, seldom concerned on the pattern of synergic innovation behavior and measurement on behavior, which deserve further investigation [56-60].

Secondly, research on synergic innovation effect, mainly included performance evaluation and its influence factors to synergic innovation. Performance evaluation on synergic innovation refers to evaluation index system, evaluation method, reliability and validity of evaluation [61]. Influence factors to performance of synergic innovation covered enterprise, government, research institutions, regional environment, and forms of cooperation and so on [62].

Thirdly, research on the driving mechanism, what was the driving force of synergic innovation? What were the obstacles to synergic innovation? How did these factors influence decision-making of synergic innovation? To answer these questions, must deeply analyze the driving mechanism of synergic innovation. For this purpose, further studies should be conducted though quantitative and qualitative analysis.

\section{Acknowledgment}

This work was supported by National Natural Science Foundation of China under Grant 71163021; Jiangxi Province Department of Education under Grant GJJ14279; and 2011 Collaborative Innovation Center of JXDSSDMAA

\section{References}

1. Chesbrough HW (2003) Open Innovation: The new imperative for creating and profiting from technology. Boston: Harvard Business School Press.

2. Cynthia A, Hall L (1992) Innovation and Competitive Advantage: What We Know and What We Need to Learn. Journal of Management 18: 399-429.

3. Jin C, Hui Y, Fang $X(2014)$ The evolutionary games simulation on industry academy-research cooperation in collaborative innovation. Science and technology progress and policy 31: 1-6.

4. Jonathan $H$ (2005) A Possible declining trend for worldwide innovation, Technological Forecasting and Social Change72: 980-986.

5. Robert DW (2008) Collaborative Pull Innovation: Origins and Adoption in the New Economy. Agribusiness 24: 388-402.

6. Freeman C (1987) Technology Policy and Economic Performance. Pinter Publishers, London, UK.

7. Lundvall BA (1992) National Systems of Innovation: Towards a Theory of Innovation and Interactive Learning, Pinter Publishers, London, UK

8. OECD (1997) National innovation systems.

9. Cooke P (1992) Regional innovation systems: Competitive regulation in the new Europe. GeoForum, 23: 365-382.

10. Cooke P, Uranga MG, Etxebarria G (1998) Regional systems of innovation: an evolutionary perspective. Environment and Planning. 30: 1563-1584.

11. Yubing $H$ (2012) The theoretical model of $I-U-R$ collaborative innovation Studies in Science of Science 30: 165-174.

12. Jin C, Yinjuan $Y$ (2012) Theoretical basis and content for collaborative innovation. Studies in Science of Science 30: 161-164. 
Citation: Hu K, Tu ME (2015) Research Progress on Synergic Innovation Theory - A Literature Review. Int J Econ Manag Sci 5: 307. doi:10.4172/21626359.1000307

13. Persaud A (2005) Enhancing Synergistic Innovative Capability in Multinational Corporations: An Empirical Investigation. Journal of Product Innovation Management 22: 412-429.

14. Xuemei X, Leilei Z, Siyu L (2014) Impact of Synergic Innovation Models of SMEs on Synergic Innovation Effect: Double-Moderating Effect of Synergic Mechanism and Synergic Environment, Science of Science and management of $S$ and T 35: 72-81.

15. Hagedoorn J, Schakenraad J (1990) Inter-Firm Partnerships and Co-operation Strategies in Core technologies" in Freeman C and Soete L "New Explorations in the Economics of Technological Change", Pinter Publishers, London \& New York, USA.

16. Swink M (2006) Building Collaborative Innovation Capability. ResearchTechnology Management 49: 37-47.

17. Ines MS, David PC, Reinhilde V (2007) Licensing of university inventions: The role of a technology transfer office. International Journal of Industrial Organization 25: 483-510

18. Von HE (1988) The Sources of Innovation, Oxford University Press, Oxford Newyork, USA.

19. Baldwin C, Hippel EV (2011) Modeling a Paradigm Shift: From Produce Innovation to User and Open Collaborative Innovation. Organization Science 22: $1399-1417$

20. Wynstra F, Arjan W, Bjorn A (1999) Purchasing Involvement in Product Development. ISBM Working Paper. European Journal of Purchasing and Supply Management.

21. Clark KB, Fujimoto T (1991) Product Development Performance: Strategy, Organization, and Management in the World Auto Industry. Cambridge: Harvard Business School Press.

22. Thomas J, David F (2000) Managing collaborative innovation in complex networks: Findings from exploratory interviews, 16th Annual IMP Conference.

23. Etzkowitz H, Leydesdorff L (1995) The triple helix of university-industrygovernment relations: A laboratory for knowledge-based economic development. EASST Review 14: 14-19.

24. Chunyan Z, Henry E (2006) Triple Helix Twins: Innovation and Sustainability. Science and Public Policy 33: 77-83.

25. Carayannis EG, Campbell DFJ (2010) Triple helix, quadruple helix and quintuple helix and how do knowledge, innovation, and environment relate to each other? International Journal of Social Ecology and Sustainable Development 1: 41-69.

26. Shapiro M (2007) The triple helix paradigm in Korea: A test for new forms of capital. International Journal of Technology Management and Sustainable Development 3: 171-191.

27. Santonen T (2007) Defining a mass customization strategy for online banking. International Journal of Mass Customization 2: 95-113.

28. Heidrun H, Emre O (2005) Intermediation in innovation, International journal of industrial organization 23: 483-503.

29. Siegel D, Waldman D, Link A (2003) Assessing the impact of organizational practices on the productivity of university technology transfer offices: An exploratory study. Research Policy 32: 27-48.

30. Koenraad D, Reinhilde $V(2005)$ The role of academic technology transfer organizations in improving industry science links. Research Policy 34: 321-342.

31. Hellman T (2007) The role of patents for bridging the science to market gap. Journal of Economic behavior and Organization 63: 624-647.

32. Mantel SJ, Rosegger G (1987) The role of third-parties in the diffusion of innovations: A survey. In: Rothwell R, Bessant J (eds.). Innovation: Adaptation and Growth 123-134.

33. Bessant J, Rush H (1995) Building bridges for innovation: The role of consultants in technology transfer. Research Policy 24: 97-114.

34. Popp A (2000) Swamped in information but starved of data: Information and intermediaries in clothing supply chains. Supply Chain Management 5: 151 161.

35. Meijers E (2005) Polycentric urban regions and the quest for synergy: Is a network of cities more than the sum of the parts. Urban studies 42: 765-781.

36. Etzkowitz H, Leydesdorff $L$ (2000) The dynamics of innovation: From national systems and 'Mode 2'to a triple helix of university-industry-government relations. Research Policy 29: 109-123.

37. Ketchen Jr DJ, Thomas JB, McDaniel Jr RR (1996) Process, Content and Context: Synergistic Effects on Organizational Performance. Journal of Management 22: 231-257.

38. Simonin BL, Helleloid D (1993) Do Organizations Learn? An Empirical Test of Organizational Learning in International Strategic Alliances. Proceedings of Academy of Management 222-226

39. Laursen K, Salter A (2004) Searching high and low: What types of forms use universities as a source of innovation? Research policy 33: 1201-1215.

40. Cohen WM, Levinthal DA (1990) A absorptive capacity: A new perspective on learning and innovation. Administrative science quarterly 35: 128-152.

41. Gerben VP, Cees VB, Alfred K (2003) Success and failure of innovation: A literature review. International Journal of Innovation Management 7: 1-30.

42. Bishop K, D'Este P, Neely A (2011) Gaining from Interactions with Universities: Multiple Methods for Nurturing Absorptive Capacity. Research Policy 40: 30-40.

43. Gilsing V, Bekkers R, Bodas F, Steen V (2011) Differences in Technology Transfer Between Science-based and Development-based Industries: Transfer Mechanisms and Barriers. Technovation 31: 638-647.

44. Zeng SX, Xie XM, Tam CM (2010) Relationship between cooperation networks and innovation performance of SMEs. Technovation 30: 181-194.

45. Terry S, Erwan L (2006) Paths of commercial knowledge: Forms and consequences of university-enterprise synergy in scientist-sponsored firms. Research Policy 35: 1465-1476.

46. Schiuma G, Lerro A (2008) Knowledge based capital in building regional innovation capacity. Journal of Knowledge Management 12: 121-136.

47. Valeria A, Andrés L (2011) Firms' linkages with public research organizations in Argentina: Drivers, perceptions and behaviours. Technovation 31: 384-400.

48. Sherwood AL, Covin JG (2008) Knowledge Acquisition in University-Industry Alliances: An Empirical Investigation from a Learning Theory Perspective. Journal of Product Innovation Management 25: 162-179.

49. Greer CR, Lei D (2012) Collaborative Innovation with Customers: A Review of the Literature and Suggestions for Future Research. International Journal of Management Reviews 14: 63-84.

50. Aspremont CD, Jacquemin A (1998) Cooperative and noncooperative R\&D in duopoly with spillovers. The American Economic Review 78: 1133-1137.

51. Ketchen Jr DJ, Ireland RD, Snow CC (2007) Strategic entrepreneurship collaborative innovation, and wealth creation. Strategic Entrepreneurship Journal 1: 371-385

52. Freeman C (1991) Networks of Innovators: A Synthesis of Research Issues. Research Policy 20: 499-514.

53. Helmi B, Laure MG, Vincent B, Guillaume A (2008) Measuring innovation best practices: Improvement of an innovation index integrating threshold and synergy effects. Technovation 28: 838-854.

54. Jeremy H (2006) Intermediation and the role of intermediaries in innovation Research Policy 35: 715-728.

55. Leydesdorff L, Etzkowitz H (2003) Can the public be considered as a fourth helix in university-industry-government relations? Report on the Fourth Triple Helix Conference. Science and Public Policy 30: 55-61.

56. Leydesdorff L, Park HW, Lengyel B (2012) A routine for measuring synergy in university-industry- government relations: Mutual information as a triple-helix and quadruple-helix indicator, Scientometrics 99: 27-35.

57. Manish KS, Devi RG (2011) When do relational resources matter? Leveraging portfolio technological resources for breakthrough innovation. Academy of Management Journal 54: 797-810.

58. Narula R, Hagedoon J (1999) Innovating through strategic alliances: Moving towards international partnerships and contractual agreement. Technovation 19: 283-294.

59. Richard RN (1993) National Innovation System: A comparative analysis Oxford University Press, New York, USA. 
Citation: Hu K, Tu ME (2015) Research Progress on Synergic Innovation Theory - A Literature Review. Int J Econ Manag Sci 5: 307. doi:10.4172/21626359.1000307

Page 5 of 5

60. Toke B (2010) Industry and academia in convergence: Micro-institutional dimensions of R\&D collaboration. Technovation 30: 100-108.

61. Chunyan Z (2006) University- Industry- Government Triple Helix Model of
Innovation: Review and Introduction of Henry Etzkowitz's Triple Helix. Studies in Dialectics of Nature 22: 75-78.

62. Ying Z, Hua L (2010) Study on the synergetic operation model of IP public policy. Studies in Science of Science 28: 351-356. 